\title{
Publisher Correction: Infused-liquid-switchable porous nanofibrous membranes for multiphase liquid separation
}

Yang Wang ${ }^{1}$, Jiancheng $\mathrm{Di}^{1}$, Li Wang ${ }^{2}$, Xu Li ${ }^{1}$, Ning Wang ${ }^{1}$, Baixian Wang ${ }^{1}$, Ye Tian ${ }^{3,4}$, Lei Jiang ${ }^{2,4} \&$ Jihong Yu ${ }^{1,5}$

Nature Communications 8:575 doi:10.1038/s41467-017-00474-y; Article published online: 18 September 2017

In Table 1 of this Article, the third row in the furthest right column contains a typographical error and should read ' $\mathrm{NH}$ ', rather than 'NM', corresponding to $n$-hexane as the infused liquid.

Published online: 30 November 2017

\begin{abstract}
(c) Open Access This article is licensed under a Creative Commons Attribution 4.0 International License, which permits use, sharing, adaptation, distribution and Ceproduction in any medium or format, as long as you give appropriate credit to the original author(s) and the source, provide a link to the Creative Commons license,

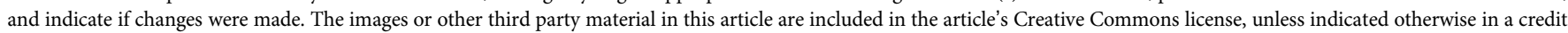
line to the material. If material is not included in the article's Creative Commons license and your intended use is not permitted by statutory regulation or exceeds the permitted use, you will need to obtain permission directly from the copyright holder. To view a copy of this license, visit http://creativecommons.org/licenses/by/4.0/.
\end{abstract}

(C) The Author(s) 2017

\footnotetext{
${ }^{1}$ State Key Laboratory of Inorganic Synthesis and Preparative Chemistry, College of Chemistry, Jilin University, Changchun 130012, China. ${ }^{2}$ Key Laboratory of Bio-inspired Materials and Interfacial Science, Technical Institute of Physics and Chemistry, Chinese Academy of Sciences, Beijing 100190, China. ${ }^{3}$ Beijing National Laboratory for Molecular Sciences (BNLMS), Key Laboratory of Green Printing, Institute of Chemistry, Chinese Academy of Sciences, Beijing 100190, China. ${ }^{4}$ University of Chinese, Academy of Sciences, Beijing 100049, China. ${ }^{5}$ International Center of Future Science, Jilin University, Changchun 130012,

China Correspondence and requests for materials should be addressed to Y.T. (email: tianyely@iccas.ac.cn) or to J.Y. (email: jihong@jlu.edu.cn)
} 